\title{
p53 regulates cell survival by inhibiting PIK3CA in squamous cell carcinomas
}

\author{
Bhuvanesh Singh, ${ }^{1,5}$ Pabbathi G. Reddy, ${ }^{1}$ Andy Goberdhan, ${ }^{1}$ Christine Walsh, ${ }^{3}$ Su Dao, ${ }^{1}$ \\ Ivan Ngai, ${ }^{1}$ Ting Chao Chou, ${ }^{2}$ Pornchai O-charoenrat, ${ }^{1}$ Arnold J. Levine, ${ }^{3}$ Pulivarthi H. Rao, ${ }^{4}$ \\ and Archontoula Stoffel ${ }^{3,5}$ \\ ${ }^{1}$ Laboratory of Epithelial Cancer Biology and ${ }^{2}$ Preclinical Pharmacology Core Facility, Memorial Sloan-Kettering Cancer \\ Center, New York, New York 10021, USA; ${ }^{3}$ Laboratory of Cancer Biology, Rockefeller University, New York, New York \\ 10021, USA; ${ }^{4}$ Children's Cancer Center, Baylor College of Medicine, Houston, Texas 77030, USA.
}

\begin{abstract}
Interactions between the $p 53$ and $P I 3 K / A K T$ pathways play a significant role in the determination of cell death/survival. In benign cells these pathways are interrelated through the transcriptional regulation of PTEN by $p 53$, which is required for p53-mediated apoptosis. PTEN exerts its effects by decreasing the phosphorylated $A K T$ fraction, thereby diminishing prosurvival activities. However, the link between these pathways in cancer is not known. In this study, PIK3CA, encoding the p110 $\alpha$ catalytic subunit of PI3K, is identified as an oncogene involved in upper aerodigestive tract (UADT) carcinomas. Simultaneous abnormalities in both pathways are rare in primary tumors, suggesting that amplification of PIK3CA and mutation of p53 are mutually exclusive events and either event is able to promote a malignant phenotype. Moreover, the negative effect of $p 53$ induction on cell survival involves the transcriptional inhibition of PIK3CA that is independent of PTEN activity, as PTEN is not expressed in the primary tumors. Conversely, constitutive activation of PIK3CA results in resistance to p53-related apoptosis in PTEN deficient cells. Thus, p53 regulates cell survival by inhibiting the PI3K/AKT prosurvival signal independent of PTEN in epithelial tumors. This inhibition is required for p53-mediated apoptosis in malignant cells.
\end{abstract}

[Key Words: P53; PI3K; cell survival; squamous cell carcinomas; head and neck neoplasms; lung neoplasms]

Received December 31, 2001; revised version accepted February 22, 2002.

Upper aerodigestive tract malignancies (UADT), including tumors arising from the head and neck, lung, and cervical esophagus, account for $18 \%$ of all cancers and $33 \%$ of all cancer deaths annually in the United States (Greenlee et al. 2000). These malignancies share a complement of genetic aberrations, hallmarked by a high prevalence of mutations in p53 (Hollstein et al. 1997). The p53 protein provides critical antagonism to tumor development by inhibiting damaged cells from progressing through the cell cycle or promoting apoptosis (Levine et al. 1994). These features explain why it is often mutated and thereby inactivated in human malignancies.

Whole genome characterization of UADT tumors by comparative genomic hybridization (CGH) identified gain and amplification at $3 \mathrm{q}$ with a high prevalence at chromosomal bands 3q26-q27 (Bjorkqvist et al. 1998; Knuutila et al. 1998; Shinomiya et al. 1999; Singh et al. 2001). This locus is of particular interest, as it has a high prevalence in multiple cancer types, displays a predilection for UADT cancers, and its presence is associated

${ }^{5}$ Corresponding authors.

E-MAIL singhb@mskcc.org; FAX (212) 717-3302.

E-MAIL stoffea@rockvax.rockefeller.edu; FAX (212) 327-7058.

Article and publication are at http://www.genesdev.org/cgi/doi/10.1101/ gad.973602. with detrimental biological and clinical consequences. Although prior studies have identified candidate genes at the $3 \mathrm{q}$ locus, controversy still exists regarding the gene $(\mathrm{s})$ that are the target of this amplification. The PIK3CA gene, located at $3 \mathrm{q} 26$, encodes the catalytic subunit $(\mathrm{p} 110 \alpha)$ of a class $\mathrm{I}_{\mathrm{A}}$ PI3K, one component of a lipidsignaling pathway involved in multiple cancer-associated functions including cell survival, proliferation, cell migration, vesicle trafficking, and vesicle budding. PIK3CA was proposed as an oncogene in cervical and ovarian cancer, but its involvement in UADT remains unclear (Shayesteh et al. 1999; Ma et al. 2000).

In this study the presence of two independent peaks of high-level amplification at 3q26.3, contained within two BAC clones is demonstrated. The alpha catalytic subunit of phosphoinositide-3-kinase (PIK3CA) is identified as a candidate oncogene involved in one of the amplified peaks in UADT carcinomas. The presence of the PIK3CA gene in a peak of amplification at 3q26.3, with corresponding RNA and protein expression, increased phosphorylated AKT protein in both cell lines and primary tumors, as well as the effects of PI3K inhibition, strongly implicate PIK3CA as one of the genes responsible for the biological consequences associated with the $3 \mathrm{q}$ amplification. 
Simultaneous mutations in p53 and amplification of PIK3CA are not found in the same tumors, strongly indicating that mutations in either pathway can render the cell refractive to programmed cell death and prone to transformation.

In normal mouse fibroblasts, several studies suggest a negative regulation of the $P I 3 K / A K T$ pathway by $p 53$ through the transcriptional activation of PTEN (Franke et al. 1997; Sabbatini and McCormick 1999; Stambolic et al. 2001). PTEN antagonizes PI3K function by dephosphorylating phosphoinositol triphosphate (PIP3), resulting in the reduction in the phosphorylated AKT fraction and $G_{1}$ arrest (Wymann and Pirola 1998).

Systematic analysis of the effects of $p 53$ on PIK3CA in EB1 colon cancer cells after UV induction shows its ability to regulate cell survival by inhibiting PIK3CA in a PTEN-dependent manner. Conversely, in UADT tumors, an alternative pathway for the inhibition of the PI3K/ $A K T$ survival pathway through $p 53$ results from the transcriptional down-regulation of PIK3CA by $p 53$ in a $P T E N$-independent manner. Moreover, it appears that the coordinated inhibition of PI3K/AKT is essential for the progression of p53-related apoptosis in PTEN deficient systems.

\section{Results}

PIK3CA as an oncogene in UADT carcinomas

Amplification of the $3 \mathrm{q} 26-27$ region is a common and crucial event in UADT carcinomas. To refine this region and identify the oncogene(s) within the 3q26-27 amplicon, 73 YAC clones were isolated spanning $\sim 38 \mathrm{cM}$ within chromosomal bands 3q26-27. Sequential dualcolor FISH with 43 of the identified YAC clones was performed on cell line MDA886, which contains the minimal amplified region identified by CGH. Based on this analysis, the apex of amplification was restricted within three highly amplified, overlapping YAC clones (803E3, 940H11, 923E6) at 3q26.3 with copy numbers ranging from $8-10$. The size of the genomic segment was determined by pulse field gel electrophoresis (PFGE) analysis of these clones and spans $\sim 1.5-2.0 \mathrm{Mb}$. To further characterize the amplification region, 39 BACs were isolated spanning the region between D3S3511 and WI6165. Sequential dual-color FISH was performed on cell line MDA886 using all 39 BAC clones. Ten BAC clones associated with high-level amplification in MDA886 were subsequently used to screen four additional head and neck carcinoma cell lines known to harbor $3 \mathrm{q}$ amplification based on CGH analysis. Two independent amplification peaks were identified within BAC clones $202 \mathrm{~B} 22$ and 386M7, with mean copy numbers of 10.6 and 10.3, respectively (Fig. 1). Analysis of BAC 386M7 showed the presence of a single gene, PIK3CA, which encodes the p110 $\alpha$ catalytic subunit of PI3K. To identify the prevalence of PI3KCA amplification, FISH analysis was performed on 20 primary tumors and 21 cell lines derived either from head and neck or lung carcinomas, using BAC $386 \mathrm{M} 7$ as a probe. The presence of amplifi-

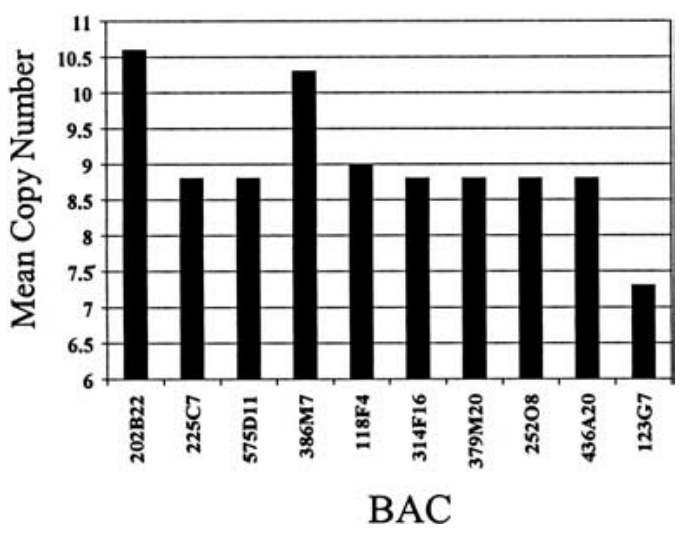

Figure 1. Identification of two amplification peaks at $3 \mathrm{q} 26.3$. FISH analysis with BAC genomic clones, of five head and neck squamous-cell carcinoma cell lines containing 3q26-27 amplification, identified two independent amplification peaks within BAC clones 202B22 and 386M7.

cation was confirmed in 13 out of 21 cell lines (62\%) with copy numbers ranging from $5-13$. In addition, highlevel amplification of PIK3CA was identified in six out of the 20 primary tumors $(30 \%)$ analyzed by FISH (Table 1).

To demonstrate the role of PIK3CA as an oncogene in UADT malignancies, semiquantitative PCR and Western blot analyses were performed on 13 head and neck and lung cancer cell lines and six primary tumors with PIK3CA amplification. Increased RNA and protein expression levels of $\mathrm{p} 110 \alpha$ were observed in 11 out of 13 cell lines and in all primary tumors examined (Fig. 2). Phosphorylated $A K T$ expression, the downstream target of PIK3CA, was present in all cases that exhibited high p110 $\alpha$ protein levels, as expected. In addition, using RTPCR, we detected $4 \times$ or greater increase in p $110 \alpha$ mRNA expression in 10 of $32(31 \%)$ squamous cell carcinomas and two of $12(17 \%)$ adenocarcinomas of the lung relative to normal lung controls. The predilection of PIK3CA expression for squamous cell histology is congruent with the reported pattern of $3 \mathrm{q}$ amplification in lung cancers (Bjorkqvist et al. 1998).

To investigate the biological effects of increased PIK3CA activity in aerodigestive tract carcinomas, six cell lines derived from head and neck or lung carcinomas with differential degrees of PIK3CA expression were treated with the PI3K specific inhibitor LY294002. Treatment with LY294002 produced a dose-dependent decrease in cell viability in all of the cell lines. The degree of response correlated with the basal level of PIK3CA expression (Fig. 2). A dose-dependent decrease in phosphorylated fraction of AKT also resulted from PI3K inhibition (Fig. 2).

The oncogenic potential of PIK3CA was also demonstrated by transfection of a constituently active PIK3CA (myrPIK3CA) in 3T3 cells. Transfection resulted in changes characteristic of malignant transformation, including increased growth rate, morphological changes, and growth in serum deficient media (Fig. 3). Anti-sense 
Singh et al.

Table 1. Status of PIK3CA and pathway components in primary head and neck squamous cell carcinomas

\begin{tabular}{|c|c|c|c|c|c|c|c|c|c|}
\hline Sample & $\begin{array}{c}\text { Tobacco } \\
\text { use }\end{array}$ & $\begin{array}{c}\text { PIK3CA } \\
\text { amplification } \\
\text { by FISH }\end{array}$ & $\begin{array}{l}\text { PIK3CA } \\
\text { RT-PCR }^{\text {b }}\end{array}$ & $\begin{array}{l}\text { PI3K-p110 } \alpha \\
\text { Western blot }\end{array}$ & Phospho-AKT & $\begin{array}{l}\text { Mutation } \\
\text { p53 }\end{array}$ & $\begin{array}{l}\text { Mutation } \\
\text { PTEN }\end{array}$ & $\begin{array}{l}\text { Methylation } \\
\text { PTEN }\end{array}$ & $\begin{array}{l}\text { PTEN } \\
\text { Western } \\
\text { blot }^{\mathrm{b}}\end{array}$ \\
\hline $4 \mathrm{TU}$ & + & - & - & - & - & + & - & - & $\downarrow$ \\
\hline $29 \mathrm{TU}$ & + & - & - & - & - & - & - & - & $\downarrow$ \\
\hline $34 \mathrm{TU}$ & + & - & - & - & - & + & - & - & $\downarrow$ \\
\hline 39TU & + & + & + & + & + & - & - & - & $\downarrow$ \\
\hline 40TU & + & - & - & - & - & + & - & - & $\downarrow$ \\
\hline $47 \mathrm{TU}$ & + & + & + & + & - & - & - & - & $\downarrow$ \\
\hline $63 \mathrm{TU}$ & + & - & - & - & - & - & - & - & $\downarrow$ \\
\hline $86 \mathrm{TU}$ & - & - & - & - & - & + & - & - & $\downarrow$ \\
\hline 97TU & + & + & + & + & + & - & - & - & $\downarrow$ \\
\hline $117 \mathrm{TU}$ & + & _- & _- & + & - & _- & - & - & $\downarrow$ \\
\hline $121 \mathrm{TU}$ & - & - & + & + & - & + & - & - & $\downarrow$ \\
\hline $140 \mathrm{TU}$ & - & - & - & - & - & - & - & - & $\downarrow$ \\
\hline $141 \mathrm{TU}$ & + & - & - & - & - & - & - & - & $\downarrow$ \\
\hline 150TU & - & - & - & - & + & - & - & - & $\downarrow$ \\
\hline $153 \mathrm{TU}$ & - & - & - & - & - & + & - & - & $\downarrow$ \\
\hline $158 \mathrm{TU}$ & + & - & - & - & + & - & - & - & $\downarrow$ \\
\hline $163 T U$ & + & + & + & + & + & - & - & - & $\downarrow$ \\
\hline $166 \mathrm{TU}$ & + & + & + & + & + & - & - & - & $\downarrow$ \\
\hline $171 \mathrm{TU}$ & - & - & - & - & - & - & - & - & $\downarrow$ \\
\hline $183 \mathrm{TU}$ & + & + & + & + & + & - & - & - & $\downarrow$ \\
\hline
\end{tabular}

${ }^{a}$ FISH performed using 386M7 BAC containing PIK3CA as the probe.

${ }^{b}$ Expression reported relative to matched normal control.

PIK3CA transfection into UADT cell lines was highly toxic, resulting in cell death in all but one of the four cell lines where stable transfections were performed. The transfection of antisense to PIK3CA (asPIK3CA) into MDA886 cells resulted in morphological changes, decreased growth rate 6.6 -fold reduction in growth rate at $72 \mathrm{~h}$ ), increased cell death (see Fig. 5, below), sensitivity to serum deficient conditions (7.1-fold increase in cell death at $72 \mathrm{~h}$ ), and loss of ability to form colonies in soft agar $(62 \%$ vs. $2 \%$ colony formation) when compared with control cells. The asPIK3CA-transfected MDA886 cells were highly sensitive to p53, with even low-level induction of UV exposure resulting in complete cell death (see Fig. 5, below).

\section{PIK3CA and PTEN are regulated by p53 in EB1 cells}

$P T E N$ is a tumor suppressor gene and a negative regulator of $A K T$, which is required for p53-mediated apoptosis in immortalized mouse embryonic fibroblasts. As in many other types of cancer, the most common genetic aberration in UADT carcinoma is mutations in the $p 53$ gene. To delineate the mechanisms of PIK3CA regulation in cancer cells, we investigated its functional interactions with p53 and PTEN utilizing a colon cancer derived $p 53$-inducible cell system. p53 was induced in EB1 cells by the introduction of $100 \mu \mathrm{M}$ zinc, resulting in transcriptional activation of $p 21$ and $M D M 2$, as well as apoptosis (Fig. 4). A fourfold induction in PTEN expression was observed, with the highest levels occurring at 20-24 h post-p53 induction. Conversely, a sixfold downregulation of PI3K $p 110 \alpha$ expression was detected by both Northern and Western blot analyses with minimal levels at $12-16 \mathrm{~h}$ post-p53 induction. A progressive decrease in phosphorylated $A K T$ levels resulted from the p53-related PTEN induction and PIK3CA inhibition. The cotreatment of EB1 with LY294002, a specific PI3K inhibitor, and induction of $p 53$ by zinc at levels associated with apoptosis resulted in strong synergism. A reduction in the level of $p 53$ induction by 6.2-fold (dose reduction index) was sufficient to induce an equivalent degree of cell death when cotreated with PIK3CA inhibitor compared with $p 53$ induction alone (Fig. 4). Taken together, these results indicate an association of the PI3K and $p 53$ pathways in cell death induction in a PTEN-dependent manner.

PIK3CA regulation by $\mathrm{p} 53$ in PTEN intact and deficient cells

To investigate whether the interaction of the $P I 3 K$ and p53 pathways is PTEN-dependent in UADT carcinomas, 16 cell lines and 20 primary tumors were subjected to PTEN gene sequencing, promoter methylation analysis, and protein expression assessment (Tables 1, 2). Mutation or promoter methylation of PTEN was seen in only one cell line each, both derived from lung cancers. However, PTEN protein was not detected in any of the head and neck cancer cell lines analyzed and was diminished at least threefold in all primary tumors relative to the matched mucosal control. In the same tumors, p53 mutations were sought by sequencing the exons containing the DNA binding domain, which is most frequently mutated in cancers. Mutations of $p 53$ were found in $30 \%$ of 
A

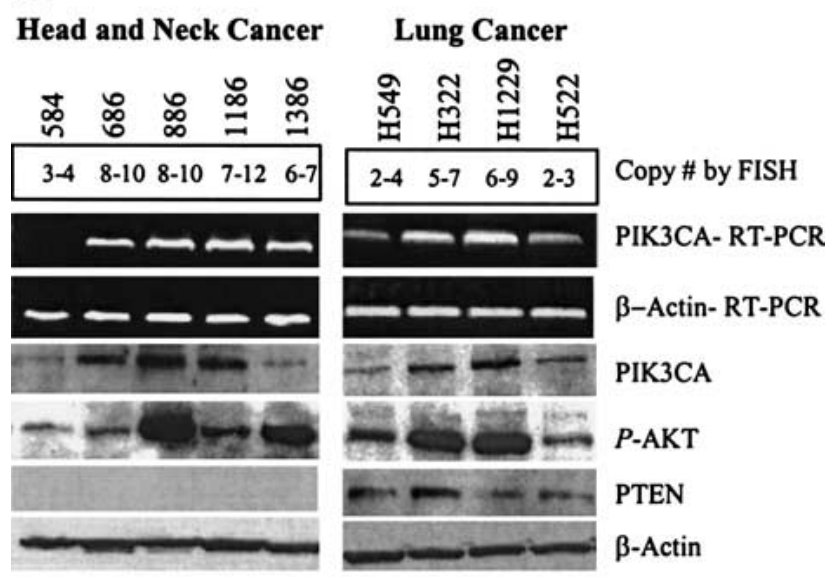

B

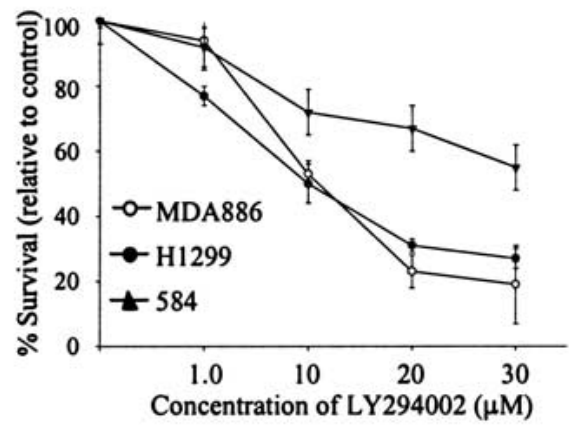

$\mathrm{C}$

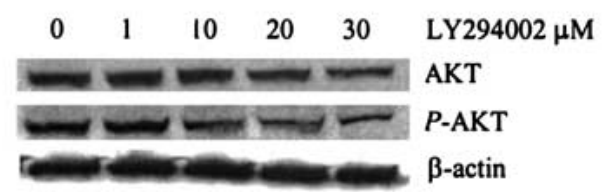

Figure 2. (A) Correlation between PIK3CA amplification, expression, and function. A high degree of correlation was detected between PIK3CA copy number by FISH, RNA expression (semiquantitative RT-PCR), and protein expression (Western blot analysis) in head and neck (left) and lung (right) carcinoma cell lines. Elevated PI3K 110 $\alpha$ expression corresponded with phosphorylated AKT levels. PTEN protein was not detected in head and neck carcinoma derived cell lines. (B) Impact of PI3K inhibition. The impact of PI3K inhibition by LY294002 on cell viability was measured by the MTT assay. A dose-dependent sensitivity was detected in all cell lines, but was highest in cell lines containing high-level PIK3CA amplification. $(C)$ Reduction of phosphorylated AKT protein levels in MDA886 resulted from PI3K inhibition by LY294002.

the primary tumors and $69 \%$ of cell lines analyzed. None of the tumors containing mutations in $p 53$ were found to have amplified PIK3CA, indicating a mutually exclusive selection of mutations in either pathway $(P=0.077 ; 95 \%$ confidence interval $=0.00-0.20$; SURGISTAT software). However, there was significant heterogeneity in the p53 and PIK3CA status in the examined cell lines, reflecting their advance genomic composition.
The effects of $p 53$ induction by UVB on PTEN and $P I K 3 C A$ transcription were assessed in cell lines derived from UADT carcinomas with intact or absent PTEN protein expression (Fig. 5). In cell line A549, induction of wild-type p53 resulted in the expected decrease in PIK3CA and increase in PTEN protein levels. The effects on phosphorylated $A K T$ levels were similar to that seen in EB1 cells. This resulted in synergism in the induction of cell death. Synergism between PIK3CA and p53 was present at all dose levels.

In cell line 886 , which has no detectable PTEN protein levels, the induction of $p 53$ still resulted in a decrease in PIK3CA expression and reduction in the phosphorylated AKT levels. The synergistic activity between $p 53$ induction and PI3K inhibition remained, but was more dosedependent and was seen at higher levels of p53 induction.

To determine the effect of PIK3CA inhibition on the p53 proapoptotic activity, we transfected a constituently active PIK3CA mutant into MDA886. This resulted in resistance to cellular death as a consequence of $p 53$ induction by UVB and had no effects on the phosphorylated $A K T$ levels. These results strongly indicate that the p53 role in regulation of cellular survival (PI3K) in epithelial tumors is independent of PTEN, which is largely not expressed in these cells or tumors.

\section{Discussion}

The PI3K/AKT cascade has been implicated in promoting cell survival downstream of extracellular stimuli (Franke et al. 1997; Wymann and Pirola 1998; Datta et al. 1999|. These stimuli mediate intracellular signaling through ligation of transmembrane receptors. Activation of these receptors results in the recruitment of PI3K isoforms to the plasma membrane that subsequently generate 3 '-phosphorylated phosphoinositides (PI3,4P, PI3,4,5). Phosphoinositol triphosphate subsequently activates PDK1, resulting in phosphorylation of AKT. Phosphorylated AKT is the active component of the pathway and has multifactorial effects resulting in the promotion of cellular survival through the inactivation of proapoptotic genes by phosphorylation.

In this study the minimal amplified region at 3q26.3 in head and neck tumors was identified in a positional cloning approach utilizing YAC and BAC clones spanning the $3 \mathrm{q}$ amplicon. Sequence analysis of the BAC clone with the highest amplification detected by FISH, identified PIK3CA as the candidate oncogene within the minimal amplified region. PIK3CA encodes for the p110 $\alpha$ catalytic subunit of $P I 3 K$, which forms a heterodimer with the $\mathrm{p} 85$-regulatory subunit and is sequestered to the cell membrane in response to multiple stimuli. Increased RNA and protein levels of PIK3CA and phosphorylated AKT, the downstream target of PIK3CA in primary tumors and cell lines, show that PIK3CA is not only amplified at the genomic level but also transcriptionally and translationally activated through the amplification. Inhibition of PIK3CA activity in six cell lines established from head and neck or lung carcinomas hav- 
Singh et al.

A

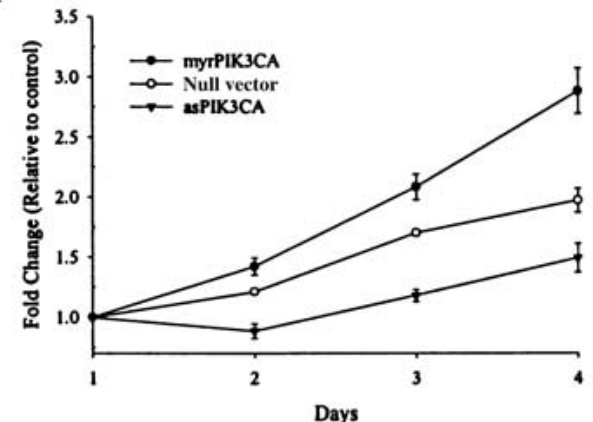

C

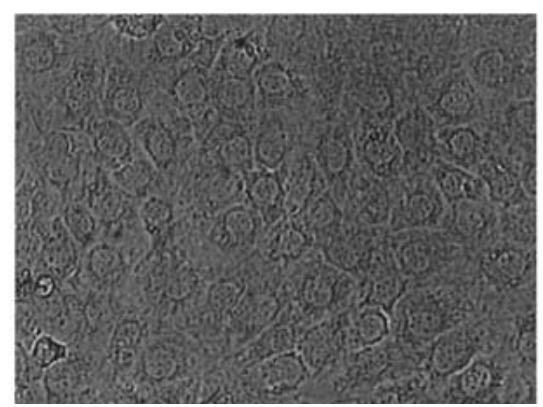

B

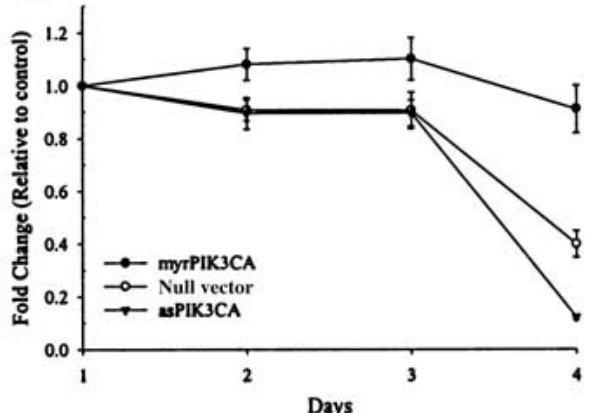

D

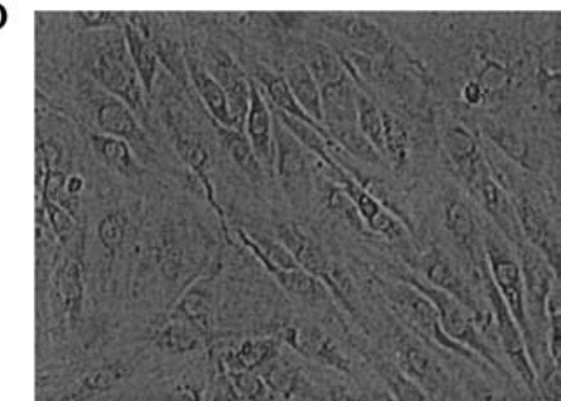

Figure 3. Transformation of 3T3 cells by PIK3CA. (A) myrPIK3CA- or asPIK3CA-transfected 3T3 cells were subjected to cell viability measurement with the MTT assay $( \pm 1$ standard deviation) showing significantly enhanced growth in myrPIK3CA-transfected cells and a growth reduction in cells transfected with asPIK3CA. (B) Preservation of growth in serum deficient media was seen in myrPIK3CAtransfected cells. $(C)$ Transfection of myrPIK3CA results in changes associated with dedifferentiation, including loss of spindle cell morphology and contact growth inhibition, compared with the null vector transfected $(D)$ cells.

ing differential degrees of PIK3CA expression produced a dose-dependent decrease in cell viability. The degree of response correlated with the basal level of PIK3CA expression and a dose-dependent decrease in phosphorylated fraction of AKT protein followed PI3K inhibition, suggesting a functional pathway for the observed impact on cellular viability. In addition, PIK3CA transfection into 3T3 cells led to morphological changes, abnormal growth, and development of colonies on soft agar. Finally, the abrogation of the malignant phenotype in MDA886 cells by transfection of antisense to PIK3CA confirms its oncogenic potential.

In summary, several lines of evidence strongly suggest that PIK3CA is the target of the $3 \mathrm{q}$ amplification: (1) the identification of PIK3CA within the minimal amplified region at $3 \mathrm{q},(2)$ the correlation between RNA and protein expression of PIK3CA, (3) the corresponding highlevel expression of phosphorylated AKT with gene amplification in both cell lines and primary tumors, (4) the deleterious effects in PI3K inhibition in cases with highlevel expression, and (5) transformation of $3 \mathrm{~T} 3$ cells after PIK3CA transfection. Given the presence of two independent peaks of amplification in the minimal common region, it remains possible that another oncogene(s) may reside at the $3 \mathrm{q} 26.3$ locus.

p53 is disrupted by mutations in many tumors and is also commonly altered in UADT tumors. Sequencing of primary tumors and cell lines detected mutations of the p53 DNA binding domain in $47 \%$ of all cases. Interestingly, none of the tumors that exhibited p53 mutations showed simultaneous amplification of PIK3CA and vice versa (Table 1). This suggests that both pathways may be functionally redundant and complement each other in UADT carcinomas.

In benign cells several lines of evidence have suggested a role for $p 53$ in negative regulation of cellular survival via binding to the PTEN promoter (Sabbatini and McCormick 1999; Henry et al. 2001). PTEN suppresses the PI3K/AKT survival signaling by dephosphorylating phosphoinositol triphosphate with subsequent reduction of the phospho-AKT fraction and $G_{1}$ arrest (Cantley and Neel 1999; Ramaswamy et al. 1999). In EB1 colon cancer cells, p53 induction resulted in a significant down-regulation of $P I 3 K / A K T$. Furthermore, simultaneous PIK3CA inhibition showed strong synergism in p53-mediated apoptosis, and p53 induction levels were decreased by 6.2 -fold (dose reduction index) with an equivalent degree of cell death. PTEN mRNA and protein levels correlated with the induced p53 levels, strongly suggesting that the negative regulation of p53 on the PI3K/AKT survival signal is PTEN-dependent in these cancer cells. Conversely, there was no detectable $P T E N$ protein in head and neck cancer cell lines and PTEN expression was diminished at least threefold relative to the matched mucosal control in all primary tumors. Induction of p53 in this tumor resulted in a decrease in PIK3CA expression and reduction in the phosphorylated AKT levels. The synergistic activity between p53 induction and PI3K inhibition remained, but was more dose-dependent and was seen at higher levels of 
PIK3CA is regulated by p53

A $\quad \begin{array}{llllllllllll}0 & 1 & 2 & 4 & 6 & 8 & 10 & 12 & 18 & 24 & \text { Hours }\end{array}$

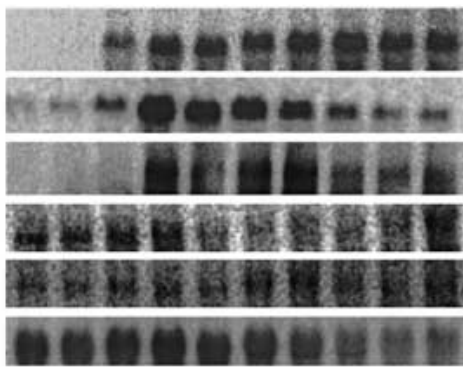

P53

$\mathrm{P} 21$

MDM2

$\mathrm{p} 110 \alpha \mathrm{PI} 3 \mathrm{~K}$

PTEN

B-Actin
B

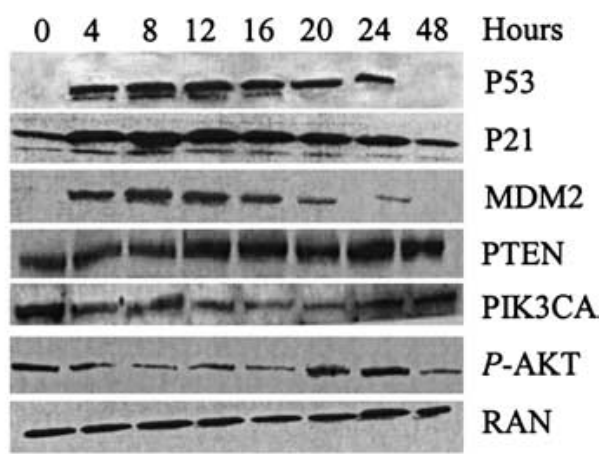

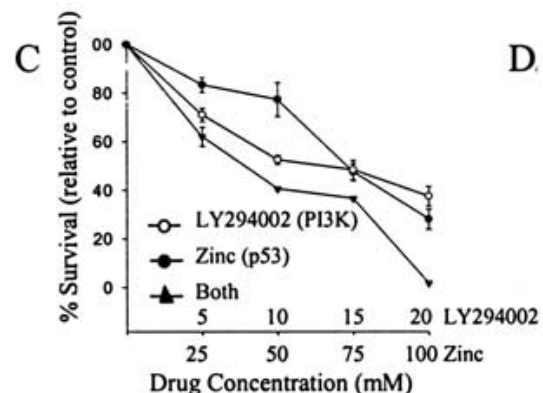
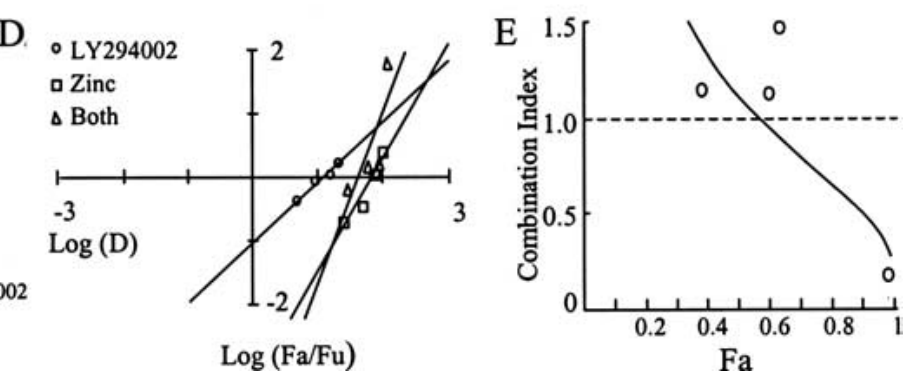

Figure 4. Effects of p53 induction on PI3K-p110 $\alpha$ and PTEN expression. Northern $(A)$ and Western $(B)$ blot analyses of EB1 cells induction of $\mathrm{p} 53$ by $100 \mu \mathrm{M}$ zinc resulted in transcriptional activation of p21 and MDM2. A fourfold induction in PTEN expression and a sixfold down-regulation of PIK3CA expression was detected by both Northern and Western blot analyses. A decrease in phosphorylated AKT levels resulted from the p53-related PTEN induction and PIK3CA inhibition. $(C, D, E)$ Results from analysis of synergism between $\mathrm{p} 53$ induction and PI3K inhibition. Significant synergism was demonstrated with p53 induction by zinc and PI3K inhibition with LY294002 in EB1 cells.

p53 induction. Finally, resistance to $p 53$-related apoptosis by transfection of a constituently active PIK3CA in MDA886 suggests that the coordinated inhibition of $P I 3 K / A K T$ is essential for $p 53$ related apoptosis in these cells and tumors.
These results strongly argue that the role of $p 53$ in the regulation of cellular survival pathway $(P I 3 K / A K T)$ involves its effects on both PTEN and PIK3CA. In head and neck tumors, the effects of p53 on $A K T$ is largely independent of its effect on PTEN, as its ex-

Table 2. Status of PIK3CA and pathway components in cell lines derived from lung and head and neck carcinomas ${ }^{a}$

\begin{tabular}{|c|c|c|c|c|c|c|c|c|}
\hline Cell line & $\begin{array}{c}\text { PIK3CA } \\
\text { amplification } \\
\text { by FISH }{ }^{b}\end{array}$ & $\begin{array}{l}\text { PIK3CA } \\
\text { RT-PCR }\end{array}$ & $\begin{array}{l}\text { PI3K-p110 } \alpha \\
\text { Western blot }\end{array}$ & $\begin{array}{c}\text { Phospho- } \\
\text { AKT }\end{array}$ & $\begin{array}{l}\text { Mutation } \\
\text { p53 }\end{array}$ & $\begin{array}{l}\text { Mutation } \\
\text { PTEN }\end{array}$ & $\begin{array}{c}\text { Methylation } \\
\text { PTEN }\end{array}$ & $\begin{array}{c}\text { PTEN } \\
\text { Western blot }\end{array}$ \\
\hline 584 & $2-3$ & - & - & + & - & - & - & - \\
\hline MDA686 & $8-9$ & ++ & ++ & + & + & - & - & - \\
\hline MDA886 & $9-12$ & +++ & +++ & +++ & - & - & - & - \\
\hline MDA1186 & $7-11$ & +++ & ++ & ++ & + & - & - & - \\
\hline MDA1386 & $5-9$ & ++ & + & +++ & + & - & - & - \\
\hline MDA1586 & $3-4$ & + & + & + & + & - & - & - \\
\hline MDA1986 & $2-3$ & + & + & + & - & - & - & - \\
\hline MSKQLL2 & $4-5$ & + & + & + & + & - & - & - \\
\hline NIH H157 & $2-3$ & + & + & + & + & + & - & + \\
\hline NIH H322 & $3-8$ & +++ & ++ & +++ & + & - & - & ++ \\
\hline NIH H1299 & $4-7$ & +++ & ++ & +++ & + & - & - & + \\
\hline NIH H522 & $2-3$ & + & + & + & + & - & - & + \\
\hline NIH H520 & $5-10$ & ++ & ++ & ++ & + & - & + & - \\
\hline NIH H2030 & $4-5$ & ++ & + & ++ & - & - & - & + \\
\hline NIH H549 & $2-3$ & + & + & ++ & - & - & - & ++ \\
\hline NIH H2170 & $2-3$ & ++ & + & + & + & - & - & + \\
\hline
\end{tabular}

${ }^{a}$ Note FISH was performed on 21 individual cell lines. Representative cell lines undergoing detailed characterization are shown in this Table.

${ }^{b}$ FISH performed using $386 \mathrm{M} 7 \mathrm{BAC}$ containing PIK3CA as the probe. 
Singh et al.

A

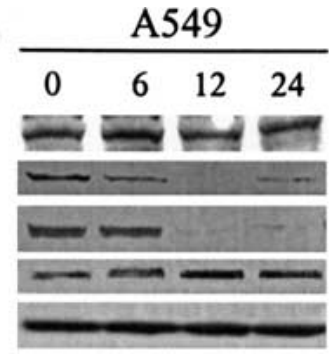

MDA886

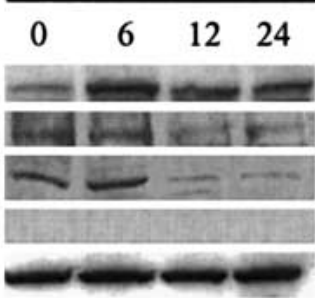

H157

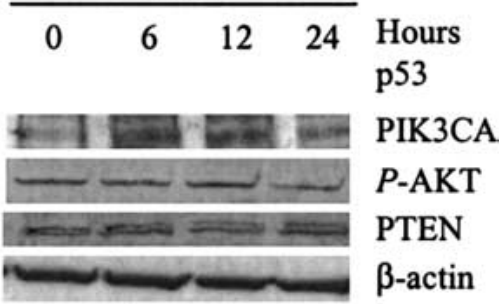

B

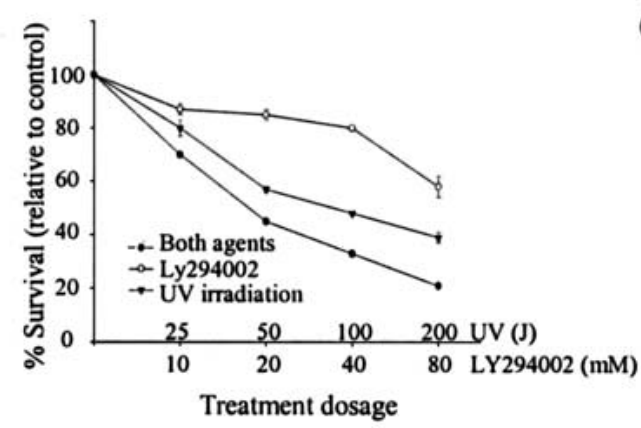

C

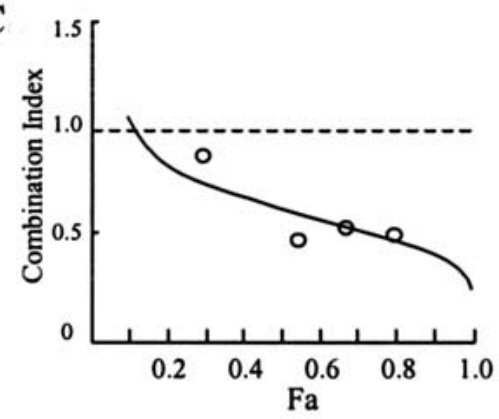

D

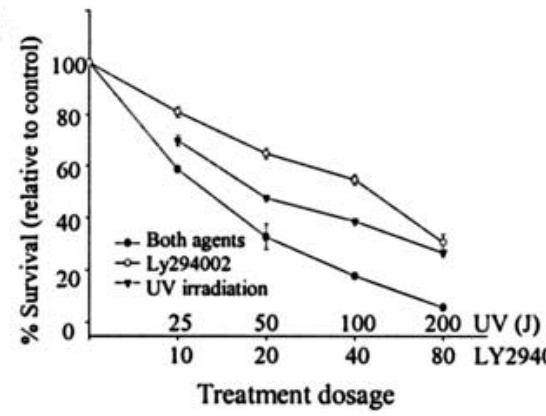

F

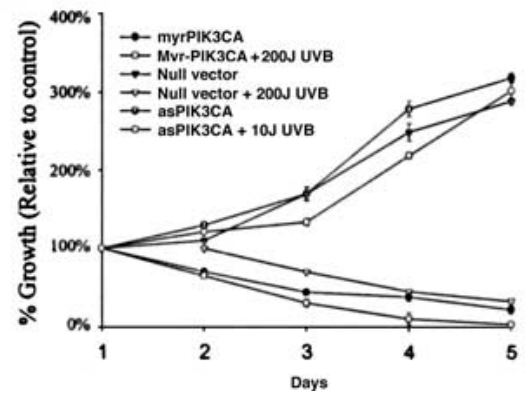

E

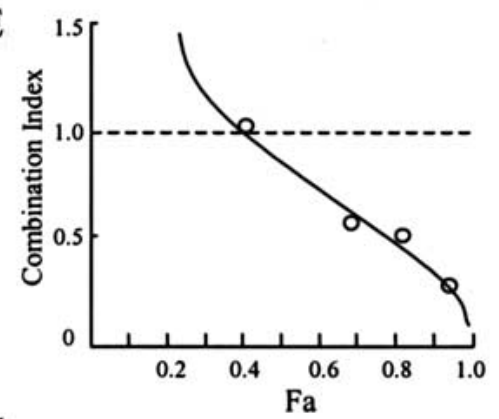

G

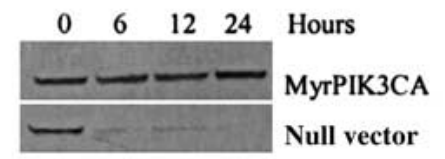

Figure 5. (A) Western blot analysis of cell lines exposed to 200J of ultraviolet irradiation (UV). In A549, with wild-type p53 and intact PTEN protein expression, UV exposure resulted in increased p53 protein expression and related increase in PTEN and decrease in PI3K p1 $10 \alpha$ and phosphorylated AKT levels. In cell line MDA886, containing wild-type p53 and no PTEN protein expression, UV exposure resulted in a decrease in PI3K p110 $\alpha$ and phosphorylated AKT protein levels. In cell line H157, containing mutated p53 and PTEN, UV irradiation had no effects on PI3K p110 $\alpha$, or AKT protein levels. $(B, C)$ Synergism analysis between p53 induction and PI3K inhibition in cell line A549 showing cell viability $(B)$ and isobologram $(C)$. Synergism was identified at all dose levels. $(D, E)$ Synergism analysis in cell line MDA 886. Synergism was detected in a dose dependent manner and to a greater extent than in cell line A549. (F,G) Transfection of myrPIK3CA into MDA886 results in resistance to p53-related apoptosis, as shown in growth curve $\mathrm{F}$ and abrogates p53-related decrease in phosphorylated AKT compared to null vector detected by Western blotting $(G)$. Transfection of asPIK3CA into MDA886 cells resulted in rapid cell death and increased sensitivity to UV irradiation $(F)$.

pression is absent or significantly reduced in these tumors. Further studies will determine if the interaction between p53 and PIK3CA is direct or if intermediate steps involving a signal mediator are required for the observed inhibitory role of p53 on PIK3CA transcription and cell survival. The relationship between $p 53$ and PIK3CA described in this work offers novel and valuable insights into the process of tumorigenesis and 
PIK3CA is regulated by p53

could well aid in the design and development of cancer treatments.

\section{Materials and methods}

\section{Cell lines and tissue resources}

Cell lines derived from head and neck squamous cell carcinomas were kindly provided by Dr. P.G. Sacks (New York University School of Dentistry, New York, NY) and those derived from lung carcinomas were purchased from the American Type Tissue Collection. EB1 is a colon tumor-derived cell line carrying a wild-type $p 53$ gene under the control of an inducible metallothionein promoter (Shaw et al. 1992; Zhao et al. 2000). Induction with $100 \mu \mathrm{M}$ zinc chloride results in sustained high levels of p53 expression and the induction of progressive apoptosis. Tumor specimens utilized in the study were obtained from sequential patients undergoing resection of carcinomas of the oral cavity or lung at Memorial Sloan-Kettering Cancer Center, following institutional guidelines. Normal mucosal tissue was also obtained from the margins of surgical resection. All tissue was snap frozen in liquid nitrogen immediately after resection and stored until use.

\section{Analysis of amplification}

YAC and BAC clones were identified by screening computerized resources at The Whitehead Institute for Biomedical Research/MIT Center for Genome Research (www.genome.wi.mit.edu) and the San Antonio Genome Center (http://apollo.utscsa.edu) as described previously (Zhao et al. 1997; Stoffel et al. 1999). Individual YAC and BAC clones were either purchased from a commercial source (Research Genetics) or kindly provided by Dr. Susan Naylor (The University of Texas Health Science Center at San Antonio). YAC and BAC clones were mapped to the $3 \mathrm{q}$ region and tested for chimerism by FISH on metaphase spreads from normal lymphocytes. The relative position of the YAC and BAC clones was accomplished by STS content PCR screening and sequential dual-color FISH analysis as described previously (Zhao et al. 1997; Stoffel et al. 1999). BAC sequences were obtained from The Human Genome Sequencing Center at the Baylor College of Medicine (www.hgsc.bcm.tmc.edu). PFGE was used to determine the size of the genomic insert according to manufacturer's protocol (Bio-Rad Laboratories).

\section{FISH}

FISH was performed and images analyzed as described previously (Singh et al. 2001).

\section{Sequence generation}

The following primers were generated using the Primer 3 program (http://www-genome.wi.mit.edu/cgi-bin/primer/primer3 www.cgi): human $\beta$-actin (accession no. XM-037239), 5' -TGGG ACGACATGGAGAAAATC-3' ' 3'-AGGGAGGAGCTGGAAG CAGC-5'; human PIK3CA (accession no. Z29090), 5'-TGTGG GACTTATTGAGG-3', 3'-CACCATGATGTGCATCATTCA$5^{\prime}$. Sequencing of $p 53$ (exons 4-9) and PTEN (exons 1-9) was performed with exon-specific primers according to manufacturer's protocol or as described previously (BD Biosciences Clontech; Liaw et al. 1997).

\section{Semiquantitative and RT-PCR}

A single step RT-PCR kit was utilized for amplification following the manufacturer's protocols (GIBCO BRL Life Technologies). PCR products were gel purified and confirmed by direct sequencing. Semiquantitative PCR was performed as described previously (Bhuyan et al. 2000). RT-PCR was performed on the iCycler iQ Real-Time Detection System (Bio-Rad Laboratories) using SYBR green detection and beta-actin for control as per manufacturer's protocols (QIAGEN).

\section{Northern blot analysis}

Twenty micrograms of total cellular RNA was extracted, size fractionated on a $1.2 \%$ agarose/formaldehyde gel, and transferred to a nylon membrane (Oncor). Hybridization was performed using standard procedures. Probes were generated for cDNA clones for PTEN (IMAGE: 322160), PI3K (IMAGE: 345430), p53 (1.6-kb insert from human p53 complete cDNA), p21 (0.5-kb NotI insert of human p21 complete cDNA), and $M D M 2$ (2.1-kb insert from human $M D M 2$ complete cDNA). For quantitation of the amount of mRNA, the Northern blots were hybridized with a human $\beta$-actin probe (Clontech).

\section{SDS-PAGE and Western blot analysis}

Proteins were resolved on SDS-polyacrylamide gels under reducing conditions and blotted onto nylon membranes (Bio-Rad Laboratories) for Western analysis according to standard procedures. Rabbit polyclonal antibodies against p110 $\alpha$ subunit of PI3K, PTEN, AKT, and phospho-AKT (Cell Signaling Technology), goat polyclonal antibodies against $\beta$-actin and PIK3CA, and monoclonal antibodies against p53 (Pab1801 [1:2]), MDM2 (4B11 [1:2]), and p21 (C19) were generated in the laboratory or obtained from a commercial source and utilized according to the manufacturer's protocols (Santa Cruz Biotechnology).

\section{PTEN promoter methylation analysis}

Promoter methylation studies were performed as described previously (Salvesen et al. 2001).

\section{Cell viability assays}

Cells were plated in 96-well plates at a density of $1 \times 10^{5}$ and treated with ultraviolet radiation, zinc, and/or LY294002 in parallel with appropriate controls. UVB irradiation was delivered using a Spectroline Shortwave UV source (Spectronics Corporation) and dose estimated using a Traceable Ultra Violet light meter (Fisher Scientific). After treatment, the cells were incubated in solution containing 3-(4,5-dimethylthiazol-2yl)-2,5-diphenyl-2 $\mathrm{H}$ tetrazolium bromide at a concentration of $0.4 \mathrm{mg} /$ $\mathrm{mL}$ for $4 \mathrm{~h}$. MTT values were measured on a MicroELISA reader (Dynatech Laboratories) at $\mathrm{OD}_{570}$. Cellular viability was calculated relative to the control group.

\section{Transfection}

Constituently active PIK3CA (myrPIK3CA) was generated using a murine $P I 3 K \mathrm{p} 110 \alpha$ under the control of the CMV promoter in pUSEamp, activated by the addition of the avian src myristoylation sequence (MGSSKSKPK) at the $\mathrm{N}$ terminus (Upstate Biotechnology). Antisense to the full-length PI3K p110 $\alpha$ cDNA (asPIK3CA) was generated as described previously (Alper et al. 2000). Cells were transfected with pUSEamp vector without an insert to serve as a control (nvPIK3VA). Transfections 
Singh et al.

were performed using the Lipofectamine Plus Reagent Kit according to the manufacturer's protocols (GIBCO BRL), under neomycin selection for stable transfection.

\section{Analysis of synergism}

To determine whether synergistic, additive, or antagonistic effects were achieved in vitro, cell lines were treated both singly and with two modes of treatment in combination. The combination ratio was selected near the $\mathrm{IC}_{50}$ ratio for each agent. Each drug and their combinations at five serial twofold dilution concentrations were used for cell growth inhibition assays to generate dose-effect relationships. The median-effect plot and the combination index (CI)-isobologram method of Chou-Talalay (Chou and Talalay 1984; Chou et al. 1994) and commercially available analytic software (CalcuSyn for Windows, Biosoft) were used to analyze the experimental data. $\mathrm{CI}<1, \mathrm{CI}=1$, and $\mathrm{CI}>1$ quantitatively indicate synergism, additive effect, and antagonism, respectively. The dose-reduction index (DRI) generated by the computer program denotes the folds of dose reduction allowed for each drug in the combination when compared with each agent alone, at a given effect level.

The median-effect equation (Eq.1) is used to calculate the dose effect relationship parameters: $f_{\mathrm{a}} / f_{\mathrm{u}}=\left(\mathrm{D} / \mathrm{D}_{m}\right)^{m}(\mathrm{Eq} .1)$, which can be rearranged to $\mathrm{D}=\mathrm{D}_{\mathrm{m}}\left[f_{\mathrm{a}} /\left(1-f_{\mathrm{a}}\right)\right]^{1 / m}$ where $\mathrm{D}$ is dose, $\mathrm{D}_{\mathrm{m}}$ is the median-effect dose, $f_{\mathrm{a}}$ and $f_{\mathrm{u}}$ are the fractions inhibited and uninhibited, respectively; $\mathrm{D}_{\mathrm{m}}$ is $\mathrm{IC}_{50}$ signifying potency, and $m$ denotes the shape of the dose-effect curve in which $m=1,>1$, and $<1$ which indicates hyperbolic, sigmoidal, and flat sigmoidal shapes, respectively. The logarithmic form of Eq.1 gives $\log \left(f_{\mathrm{a}} / f_{\mathrm{u}}\right)=m \log (\mathrm{D})-\operatorname{mlog}\left(\mathrm{D}_{m}\right)$ (Eq.2). Therefore, a plot of $\log \left(f_{\mathrm{a}} / f_{\mathrm{u}}\right)$ vs $\log (\mathrm{D})$ gives the slope of $m$ value and the antilog of the $y$-intercept yields the $D_{m}$ value.

The CI and the DRI can be determined by:

$$
C I=\frac{(D)_{1}}{\left(D_{X}\right)_{1}}+\frac{(D)_{2}}{\left(D_{X}\right)_{2}} \quad \frac{1}{(D R I)_{1}} \quad \frac{1}{(D R I)_{2}}
$$

where $D_{x}$ is the dose for $\mathrm{x} \%$ inhibition. For $F_{\mathrm{a}}$ at $\mathrm{x} \%$ affected by $\mathrm{D}_{1}, \mathrm{D}_{2}$, or their mixture (i.e., at isoeffective doses) and in the mixture where $\left(D_{x}\right)_{1,2}=(D)_{1}+(D)_{2}$ and $(\mathrm{D})_{1} /(\mathrm{D})_{2}=\mathrm{P} / \mathrm{Q}$. Substituting Eq. 1 into Eq. 3, produced:

$C I$

$$
=\frac{\left(D_{\mathrm{x}}\right)_{1,2}[P /(P+Q)]}{\left.\left(D_{m}\right)_{1}\left\{\left(f \mathrm{a}_{\mathrm{x}}\right)_{1} / 1-\left(f \mathrm{a}_{\mathrm{x}}\right)_{1}\right]\right\}^{1 / \mathrm{m}_{1}}}+\frac{\left(\mathrm{D}_{\mathrm{x}}\right)_{1,2}[\mathrm{Q} /(\mathrm{Q}-\mathrm{P})]}{\left.\left(\mathrm{D}_{\mathrm{m}}\right)_{2}\left\{\left(f \mathrm{a}_{\mathrm{x}}\right)_{2} / 1-\left(f \mathrm{a}_{\mathrm{x}}\right)_{2}\right]\right\}^{1 / \mathrm{m}_{2}}}
$$

(Eq. 4)

where $\quad\left(D_{x}\right)_{1,2}=\left[\left(f a_{x}\right)_{1,2} /\left[1-\left(f a_{x}\right)_{1,2}\right]\right\}^{1 / m_{1,2}}\left[\left(D_{m}\right)_{1,2}\right]$

and $\quad\left(f a_{x}\right)_{1}=\left(f a_{x}\right)_{2}=\left(f a_{x}\right)_{1,2} \quad$ (i.e., isoeffective)

\section{Acknowledgments}

We thank Conal O'Carroll for his thoughtful suggestions and review of the manuscript, Dr. Susan Naylor for providing the BAC clones used in this study, Dr. Raju S.K. Chaganti for his guidance and assistance with molecular cytogenetic analyses, and Swarna Gogineni for her excellent technical assistance.

The publication costs of this article were defrayed in part by payment of page charges. This article must therefore be hereby marked "advertisement" in accordance with 18 USC section 1734 solely to indicate this fact.

\section{References}

Alper, O., De Santis, M.L., Stromberg, K., Hacker, N.F., ChoChung, Y.S., and Salomon, D.S. 2000. Anti-sense suppression of epidermal growth factor receptor expression alters cellular proliferation, cell-adhesion, and tumorigenicity in ovarian cancer cells. Int. J. Cancer 88: 566-574.

Bhuyan, D.K., Reddy, P.G., and Bhuyan, K.C. 2000. Growth factor receptor gene and protein expressions in the human lens. Mech. Aging Dev. 113: 205-218.

Bjorkqvist, A.M., Husgafvel-Pursiainen, K., Anttila, S., Karjalainen, A., Tammilehto, L., Mattson, K., Vainio, H., and Knuutila, S. 1998. DNA gains in 3q occur frequently in squamous cell carcinoma of the lung, but not in adenocarcinoma. Genes Chromosomes Cancer 22: 79-82.

Cantley, L.C. and Neel, B.G. 1999. New insights into tumor suppression: PTEN suppresses tumor formation by restraining the phosphoinositide 3-kinase/AKT pathway. Proc. Natl. Acad. Sci. 96: 4240-4245.

Chou, T.C. and Talalay, P. 1984. Quantitative analysis of doseeffect relationships: The combined effects of multiple drugs or enzyme inhibitors. Adv. Enzyme Regul. 22: 27-55.

Chou, T.C., Stepkowski, S.M., and Kahan, B.D. 1994. Computerized quantitation of immunosuppressive synergy for clinical protocol design. Transplant Proc. 26: 3043-3045.

Datta, S.R., Brunet, A., and Greenberg, M.E. 1999. Cellular survival: A play in three Akts. Genes \& Dev. 13: 2905-2927.

Franke, T.F., Kaplan, D.R., and Cantley, L.C. 1997. PI3K: Downstream AKT action blocks apoptosis. Cell 88: 435-437.

Greenlee, R.T., Murray, T., Bolden, S., and Wingo, P.A. 2000. Cancer statistics, 2000. CA Cancer J. Clin. 50: 7-33.

Henry, M.K., Lynch, J.T., Eapen, A.K., and Quelle, F.W. 2001. DNA damage-induced cell-cycle arrest of hematopoietic cells is overridden by activation of the PI-3 kinase/Akt signaling pathway. Blood 98: 834-841.

Hollstein, M., Soussi, T., Thomas, G., von Brevern, M.C., and Bartsch, H. 1997. p53 gene alterations in human tumors: Perspectives for cancer control. Recent Results Cancer Res. 143: 369-389.

Knuutila, S., Bjorkqvist, A.M., Autio, K., Tarkkanen, M., Wolf, M., Monni, O., Szymanska, J., Larramendy, M.L., Tapper, J., Pere, H., et al. 1998. DNA copy number amplifications in human neoplasms: Review of comparative genomic hybridization studies. Am. J. Pathol. 152: 1107-1123.

Levine, A.J., Chang, A., Dittmer, D., Notterman, D.A., Silver, A., Thorn, K., Welsh, D., and Wu, M. 1994. The p53 tumor suppressor gene. J. Lab. Clin. Med. 123: 817-823.

Liaw, D., Marsh, D.J., Li, J., Dahia, P.L., Wang, S.I., Zheng, Z., Bose, S., Call, K.M., Tsou, H.C., Peacocke, M., et al. 1997. Germline mutations of the PTEN gene in Cowden disease, an inherited breast and thyroid cancer syndrome. Nat. Genet. 16: 64-67.

Ma, Y.Y., Wei, S.J., Lin, Y.C., Lung, J.C., Chang, T.C., WhangPeng, J., Liu, J.M., Yang, D.M., Yang, W.K., and Shen, C.Y. 2000. PIK3CA as an oncogene in cervical cancer. Oncogene 19: 2739-2744.

Ramaswamy, S., Nakamura, N., Vazquez, F., Batt, D.B., Perera, S., Roberts, T.M., and Sellers, W.R. 1999. Regulation of $\mathrm{G}_{1}$ progression by the PTEN tumor suppressor protein is linked to inhibition of the phosphatidylinositol 3-kinase/Akt pathway. Proc. Nat1. Acad. Sci. 96: 2110-2115.

Sabbatini, P. and McCormick, F. 1999. Phosphoinositide 3-OH kinase (PI3K) and PKB/Akt delay the onset of p53-mediated transcriptionally dependent apoptosis. J. Biol. Chem. 274: 24263-24269.

Salvesen, H.B., MacDonald, N., Ryan, A., Jacobs, I.J., Lynch, 
E.D., Akslen, L.A., and Das, S. 2001. PTEN methylation is associated with advanced stage and microsatellite instability in endometrial carcinoma. Int. J. Cancer 91: 22-26.

Shaw, P., Bovey, R., Tardy, S., Sahli, R., Sordat, B., and Costa, J. 1992. Induction of apoptosis by wild-type p53 in a human colon tumor-derived cell line. Proc. Natl. Acad. Sci. 89: 4495-4499.

Shayesteh, L., Lu, Y., Kuo, W.L., Baldocchi, R., Godfrey, T., Collins, C., Pinkel, D., Powell, B., Mills, G.B., and Gray J.W. 1999. PIK3CA is implicated as an oncogene in ovarian cancer. Nat. Genet. 21: 99-102.

Shinomiya, T., Mori, T., Ariyama, Y., Sakabe, T., Fukuda, Y., Murakami, Y., Nakamura, Y., and Inazawa, J. 1999. Comparative genomic hybridization of squamous cell carcinoma of the esophagus: The possible involvement of the DPI gene in the 13q34 amplicon. Genes Chromosomes Cancer 24: 337-344.

Singh, B., Gogineni, S.K., Sacks, P.G., Shaha, A.R., Shah, J.P., Stoffel, A., and Rao, P.H. 2001. Molecular-cytogenetic characterization of head and neck squamous cell carcinoma and refinement of 3q amplification. Cancer Res. 61: 4506-4513.

Stambolic, V., MacPherson, D., Sas, D., Lin, Y., Snow, B., Jang, Y., Benchimol, S., and Mak, T.W. 2001. Regulation of PTEN transcription by p53. Mol. Cell 8: 317-325.

Stoffel, A., Rao, P.H., Louie, D.C., Krauter, K., Liebowitz, D.N., Koeppen, H., Le Beau, M.M., and Chaganti, R.S. 1999. Chromosome 18 breakpoint in $\mathrm{t}(11 ; 18)(\mathrm{q} 21 ; \mathrm{q} 21)$ translocation associated with MALT lymphoma is proximal to BCL2 and distal to DCC. Genes Chromosomes Cancer 24: 156-159.

Wymann, M.P. and Pirola, L. 1998. Structure and function of phosphoinositide 3-kinases. Biochim. Biophys. Acta. 1436: $127-150$.

Zhao, N., Stoffel, A., Wang, P.W., Eisenbart, J.D., Espinosa, III, R., Larson, R.A., and Le Beau, M.M. 1997. Molecular delineation of the smallest commonly deleted region of chromosome 5 in malignant myeloid diseases to $1-1.5 \mathrm{Mb}$ and preparation of a PAC-based physical map. Proc. Natl. Acad. Sci. 94: 6948-6953.

Zhao, R., Gish, K., Murphy, M., Yin, Y., Notterman, D., Hoffman, W.H., Tom, E., Mack, D.H., and Levine, A.J. 2000. Analysis of p53-regulated gene expression patterns using oligonucleotide arrays. Genes \& Dev. 14: 981-993. 


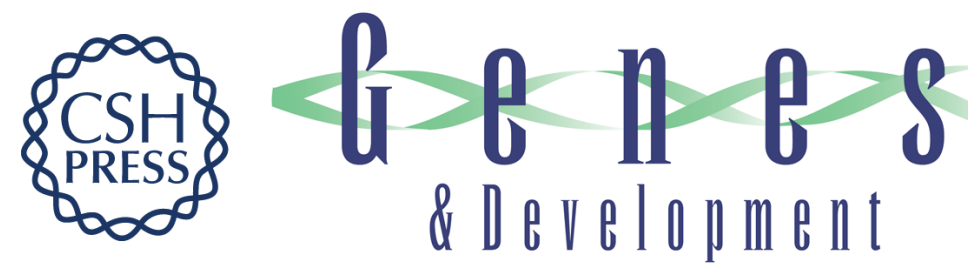

\section{p53 regulates cell survival by inhibiting PIK3CA in squamous cell carcinomas}

Bhuvanesh Singh, Pabbathi G. Reddy, Andy Goberdhan, et al.

Genes Dev. 2002, 16:

Access the most recent version at doi:10.1101/gad.973602

References This article cites 26 articles, 9 of which can be accessed free at: http://genesdev.cshlp.org/content/16/8/984.full.html\#ref-list-1

\section{License}

Email Alerting Receive free email alerts when new articles cite this article - sign up in the box at the top right corner Service of the article or click here.

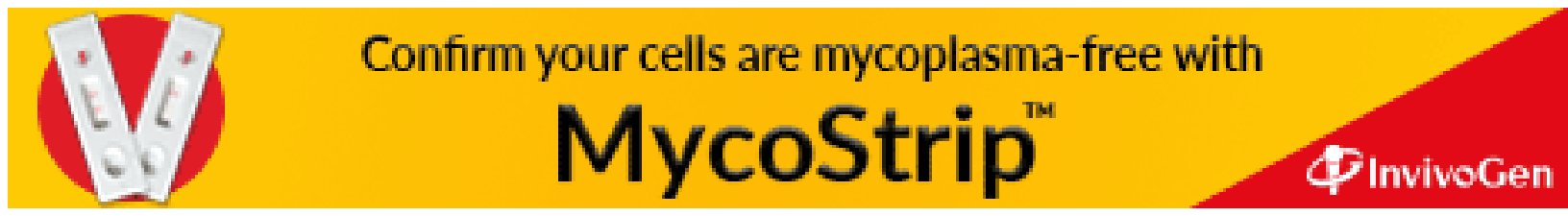

